\section{O ÓCIO NAS CULTURAS CONTEMPORÂNEAS: TEORIAS E NOVAS PERSPECTIVAS EM INVESTIGAÇÃO}

\author{
The Leisure in Contemporary Cultures: Theories and New \\ Perspectives in Research
}

\begin{abstract}
El Ocio en las Culturas Contemporaneas: Teorías y Nuevas Perspectivas en Investigación
\end{abstract}

\author{
Le Loisir dans las Cultures Contemporaines: Théories et \\ Nouvelles Perspectives pour la Recherche
}

O estudo do ócio nos países de língua portuguesa ganha uma valiosa contribuição. Trata-se do livro O Ócio nas Culturas Contemporâneas - Teorias e Novas Perspectivas em Investigação que teve o seu lançamento na UNIFOR, por ocasião do VII Seminário Ócio e Contemporaneidade, em agosto de 2013, como resultado de nucleação de pesquisa entre a Universidade de Fortaleza, no Brasil e a Universidade de Aveiro, em Portugal.

A obra apresenta reflexões sobre ócio, tempo livre e lazer nas culturas contemporâneas numa perspectiva transdisciplinar, envolvendo trabalhos de três grupos de investigadores: um grupo de Portugal que trabalha no contexto do Programa Doutoral em Estudos Culturais da Universidade de Aveiro e do Minho; um segundo grupo, da Espanha, que tem como referencial os estudos multidisciplinares desenvolvidos no Instituto de Estudos do Ócio da Universidade de Deusto; e o terceiro grupo, do Brasil, a partir das investigações desenvolvidas no Laboratório de Estudos sobre Ócio, Trabalho e Tempo Livre, do Programa de Pós-Graduação em Psicologia da Universidade de Fortaleza, que mantém interfaces com diversos grupos de estudos no Brasil sobre os temas em foco.

Os organizadores da obra são o professor José Clerton Martins, da Universidade de Fortaleza, Brasil e a professora Maria Manuel Baptista, da Universidade de Aveiro, Portugal. O volume, que se apresenta em formato normal em papel e, atendendo à demanda tecnológica da contemporaneidade, encontra-se também no formato de e-book (pdf), está estrategicamente bem dividido em dois grandes blocos. O primeiro, intitulado "Um olhar multidisciplinar sobre o ócio - mobilizar teorias e desenhar genealogias", eminentemente teórico, é composto por sete capítulos. Os cinco primeiros capítulos são conceituais, filosóficos e epistemológicos, e os dois últimos são mais voltados para a prática e a experiência do ócio. Na parte mais teórica são abordados: conceitos relacionados ao tempo livre, ócio e lazer, convocando também o conceito de experiência; uma epistemologia sobre ócio e trabalho; uma leitura filosófica do ócio, a partir da fenomenologia e hermenêutica heideggereana; uma reflexão sobre o ócio à luz da estética baumgarteniana; e um resgate do paradigma do sábado na mitologia hebreia. Na parte final deste primeiro bloco, mais voltada para a prática, são apresentados: uma reflexão poética sobre a experiência de ócio na literatura e um resgate da experiência temporal de Kairós na prática esportiva recreativa.
Resenha

\author{
José Júlio Martins Tôrres ${ }^{(1)}$
}

1)

Doutorando em Psicologia.
Recebido em: 10/03/2014

Revisado em: 15/01/2015 Aceito em: 13/03/2015 
Já o segundo bloco, denominado de "Perspectivas emergentes em estudos do ócio", mais voltado para estudos empíricos, se compõe de nove capítulos em que a proporção do teórico versus prático é invertida. O primeiro desses nove capítulos apresenta a teoria do ócio na perspectiva humanista proposta pelo Instituto de Estudos de Ócio da Universidade de Deusto. O capítulo seguinte, que aponta as possibilidades de ócio e de lazer se manifestarem como realidades na contemporaneidade, abre caminho para os sete capítulos que se seguem e que apresentam estudos empíricos sobre vivências do tempo livre, do ócio, do lazer e da animação sociocultural.

Assim, a obra contém 16 capítulos estrategicamente distribuídos, de maneira a proporcionar uma reflexão sobre o ser humano na sua relação com suas elaborações temporais, suas vivências e significados nas culturas contemporâneas. Feitas estas considerações gerais, apresentamos, a seguir, um breve detalhamento de cada um dos capítulos.

O primeiro capítulo "Tempo Livre, Ócio e Lazer: sobre Palavras, Conceitos e Experiências" é muito esclarecedor sobre estes conceitos centrais, cuja compreensão ainda permanecia um pouco obscura para muita gente. Partindo da ideia de consumo na dimensão hiper, como guia dos estilos de vida; de reflexão sobre a aceleração social, que leva a vivermos simultaneamente muitas experiências, acarretando um empobrecimento das experiências vivenciadas na contemporaneidade; e convocando, também, o conceito de experiência, José Clerton Martins deixa bem claro os distanciamentos e as aproximações que envolvem os termos Tempo Livre, Ócio e Lazer, principalmente na realidade brasileira. Por fim, ócio é apresentado como uma condição do ser humano, uma experiência sem objetivos financeiros, necessária para o enriquecimento da natureza humana, integrante da condição de ser, uma experiência transformadora que define a experiência humana em si.

No segundo capítulo, "Ensaiando uma Epistemologia sobre os Termos Ócio e Trabalho", Viktor D. Salis apresenta uma revisão bibliográfica de textos clássicos, resgatando conceitos pensados originalmente para formar o homem obra de arte, na Paideia Grega. Mostra, então, como, ao longo da história da cultura ocidental, os conceitos de ócio e trabalho foram empobrecidos pela apreensão utilitarista consumista. $\mathrm{O}$ autor dá uma verdadeira aula de epistemologia sobre os termos associados a ócio e trabalho, mostrando como se deu a redução de seus significados desde os significados originais, na Grécia antiga, com a Psicagogia, passando por Roma e chegando até os nossos dias, em especial, no Brasil. Ao final, apresenta as possibilidades do trabalho para além dessas simplificações ocorridas ao longo da história e o papel do ócio criador tal como era fundamental na sociedade arcaica grega, quando proporcionava o verdadeiro sentido do existir. $\mathrm{O}$ autor conclui que, para que a experiência de ócio seja possível, a nossa consciência deve nos orientar a gastar o tempo que temos, não com finalidade lucrativa, mas sim, pela própria ação em si.

Em "Ócio, Temporalidade e Existência: uma leitura à luz da fenomenologia e hermenêutica heideggereana", no terceiro capítulo, Maria Manuel Baptista desenvolve uma reflexão sobre ócio, tempo, temporalidade e existência, na perspectiva do ser-aí (dasein) heideggereano. Ao discorrer sobre ócio e tempo (livre), apresenta o desapontamento do ser humano com a sua dimensão de temporalidade nas culturas contemporâneas. Em seguida, apresenta de forma simples, porém muito esclarecedora e com muita lucidez, o ócio nas culturas contemporâneas, destacando: as dimensões psicossociais e culturais; a dimensão ontológica-existencial e a relação do ócio com arte e verdade, na perspectiva heideggereana. Conclui sugerindo um projeto poiético do ócio, que passa a ser um desafio à nossa existência. Devemos, então, nos preparar, com esforço e dedicação, para dispormos das condições educativas e culturais que nos tornem realmente humanos. E isso só é possível se dispusermos de tempo para viver o pleno ócio.

Em uma outra visão filosófica, Carlos Velázquez Rueda, no quarto capítulo, "Reflexões sobre o ócio baumgarteniano", sugere que a chave da questão está na percepção da situação por meio dos sentidos internos e externos. Para demonstrar isso, o autor se vale da epistemologia estética baumgarteniana, estendendo-a para os processos cognitivos gerais. De certa forma, já preparando o terreno para os dois capítulos finais deste primeiro bloco do livro, sugere que a prática do ócio deve ocorrer sob a concepção de que a teoria de qualquer fenômeno não pode ser separada da sua experimentação prática. $\mathrm{O}$ autor afirma que a posse intelectual dos princípios essenciais, sem a devida confrontação com as funções das suas variáveis práticas, nos deixa afastados do real. Finaliza denunciando a racionalização da cadeia produtiva, o que desemboca na programação da obsolescência estética dos produtos, provocando o trunfo contemporâneo do esteticismo e, por consequência, a negação do ócio pela exacerbação do negócio.

No quinto capítulo, "Entre o ócio sagrado e a sacralização do ócio", Simão Silva apresenta o processo de secularização do tempo e espaço na sociedade contemporânea e revisita o paradigma do sábado na mitologia hebreia para explicar o tempo de parar, representado pelo sétimo dia como uma forma de viver o ócio para o desenvolvimento humano. Começa por descrever o ócio sagrado como uma paragem do próprio Criador e apresenta a sacralização do ócio como a essência do desenvolvimento humano, pois a paragem consagra o ser a partir da liberdade sobre o uso do tempo. Termina concluindo que a sociedade contemporânea, por não fazer a gestão do tempo, dessacralizou o ócio, tornando-o um produto descartável. Propõe, então, que o sétimo dia seja entendido como arte de bem viver o ócio para o desenvolvimento humano.

O sexto e o sétimo capítulos, fechando o primeiro 
bloco, apresentam duas possibilidades práticas de experiência de ócio, uma na literatura e outra na prática esportiva recreativa. No sexto capítulo, "A literatura como experiência de ócio na pós-modernidade", Anne Ventura apresenta uma reflexão poética sobre a experiência literária, mostrando que a literatura como arte está relacionada ao ócio porque o tempo a ela dedicado, além de livre, é libertador. Além disso, o leitor dá nova vida ao poema ao lê-lo, dando-lhe sentido íntimo, ao mesmo tempo em que a poesia gera metamorfose no leitor. No sétimo capítulo, "Ócio e prática esportiva recreativa: via régia para o desenvolvimento de sinergias entre corpo, tempo e cultura na sociedade de consumo", Maria Inês Bittencourt e Paula Duarte apresentam a importância da ação corporal na experiência subjetiva, enfocando a afetividade e o sensóriomotor relacionados à temporalidade e à cultura, a partir do conceito de Kairós - o tempo oportuno. Finalizam, apresentando a prática esportiva como atividade do ócio criador por considerar essa atividade geradora de novas significações para a existência. E asseguram que essas experiências, além de corporais, são emocionais e afetivas, ajudando na formação do eu.

O oitavo capítulo, "A perspectiva humana do ócio: revisitando a proposta do instituto de Deusto", abre o segundo bloco do livro, denominado de "Perspectivas emergentes em estudos do ócio". Nele, Francisco Francileudo faz um percurso muito esclarecedor acerca das investigações sobre o ócio humanista preconizado pela equipe da Universidade de Deusto, que trata o ócio como uma experiência subjetiva e uma dimensão da condição humana. Por fim, apresenta os possíveis benefícios da experiência de ócio e a sua importância para o desenvolvimento pessoal, social, econômico e para a melhoria da qualidade de vida. Em sua conclusão, o autor aponta que o fundamental da experiência é o despertar da dignidade do ser humano e destaca entre os benefícios do ócio: a percepção de liberdade - que leva a um sentimento de plenitude e prazer; e o desfrute, o descanso e a evasão - que proporcionam o sentimento de autorrealização.

No capítulo nove, "Ócio e lazer: das possibilidades às realidades na contemporaneidade", Ieda Rhoden, Clerton Martins e Katia Flores apresentam as possibilidades para os usos do tempo livre, do lazer e da experiência de ócio e mostram como estes usos estão acontecendo na contemporaneidade, de modo especial, no espaço urbano. Finalizam o capítulo mostrando suas inquietações com os meios de lazer industrializado, que provocam a substituição do ser pelo ter e pelo imaginar ter, gerando grandes angústias para o ser humano e afastando os indivíduos das verdadeiras experiências de ócio construtivo.

O décimo capítulo, "A vivência do tempo livre em jogos MMORPG: interação e sociabilidade" adentra uma área muito importante na contemporaneidade que é a das novas tecnologias de informação e comunicação. Nele,
Daniel Abs e Jorge Castellá Sariera apresentam a realidade das linguagens digitais e das relações nas redes sociais, mostrando como os jovens vivenciam o seu tempo livre no envolvimento com esse ambiente tecnológico, em especial nos jogos MMORPG - Massive Multplayer Online RolePlay Games, criando possibilidades para suas experiências. Finalizam, destacando os games, os sites, fóruns e comunidades sociais como espaços de integração.

No décimo primeiro capítulo: "A gratuidade no ócio: a partilha de ficheiros mata ou promove o autor?", Sofia Buchholz e Jorge Teixeira discorrem sobre a gratuidade do ócio, também num contexto tecnológico que envolve a polêmica do compartilhamento de livros em formato digital na Internet, refletindo sobre as implicações na divulgação e nas vendas das obras. Mostram que, num contexto de elevada pirataria, as opiniões dos autores de livros se dividem e dificilmente se chegará a um consenso. Por fim, é destacada a importância da "Marca-autor" e a questão da gratuidade do ócio, sugerindo que os autores de livros devem aproveitar essas novas tecnologias para gerarem formas de melhor se conectarem a editores, escritores e leitores, garantindo a diversidade de formato compatível com a diversidade de leitores, pois a publicação digital está crescendo em ritmo acelerado e se tornou uma fonte de novas oportunidades.

No décimo segundo capítulo, "Ler como uma forma de ver: a imaginação na vivência do ócio das crianças", Beatriz Mendes e Sílvia Cambra apresentam um estudo em que se procurou perceber a relevância que as histórias contadas em livros têm para o imaginário das crianças, nas suas experiências de ócio, em comparação a outros meios, especificamente o cinema. Depois de detalharem clara e minuciosamente a metodologia utilizada na pesquisa e os processos de geração e de análise dos dados, concluem que os livros e a sua leitura têm e sempre terão enorme influência no desenvolvimento humano, primordialmente de crianças.

No décimo terceiro capítulo, "Momo (1973), de Michael Ende, sob uma perspectiva de ócio humanista", Inês Gamelas apresenta uma ideia do ócio humanista e do romance Momo, e destaca a dimensão solidária do tempo, que no romance é também sinônimo de identidade e é utilizado como moeda de troca. Apresenta a importância da infância, considerando que a protagonista do romance é uma criança. Conclui que a ficção é impulsionadora de uma educação para o ócio, que poderá representar a alternativa na formação completa e integrada das novas gerações, principalmente durante a infância.

Com o título de "A gambiarra de Iara: sobre ócio e inventividade", o décimo quarto capítulo, de autoria de Iara Souza, apresenta uma reflexão sobre ócio a partir de uma história de vida e sobrevivência com inventividade. Mostra que o prazer de criar, na construção de gambiarras, propicia o desenvolvimento de um novo olhar e envolve ressignificações importantes para a dinâmica da geração de 
conhecimento e para o desenvolvimento humano.

No décimo quinto capítulo, "Lazer e turismo como contribuição às comunidades sustentáveis e ao desenvolvimento na escala humana", Luzia Neide Coriolano e Édima Aranha apresentam como o lazer, que é uma expressão e manifestação da sociedade contemporânea, e o turismo podem se contrapor ao trabalho na geração de sustentabilidade, propiciando participação comunitária para o desenvolvimento humano.

Finalizando o livro, no décimo sexto capítulo, "Ócio e tempo livre na idade adulta avançada: as práticas de animação sociocultural como estratégia de resiliência", Jenny Gil Souza e Maria Manuel Baptista apresentam as práticas de animação sociocultural como propiciadoras de prática de ócio humanista, podendo ser usadas como estratégias de resiliência para uma melhor convivência com os problemas frequentes na fase de idade mais avançada da vida. Sustentam que a animação e o ócio são orientados ao desenvolvimento cultural, social e educativo. Assim, a imbricação e a complementariedade entre os conceitos de ócio, animação e envelhecimento permitem recriar o sentido de velhice através do ócio por meio da animação, pois animação cultural pode transformar o tempo livre de que os idosos dispõem em tempo para ócio positivo, imprescindível para seu bem-estar e para sua qualidade de vida.

O presente livro apresenta uma abordagem sobre ócio e cultura, a partir de pontos de vista diversos, mostrando trabalhos de investigadores de vários países, com formações as mais distintas: como história, filosofia, linguística, psicologia social, sociologia, literatura, educação, desporto, geografia, música. Traz contribuições muito ricas para estudos do ócio, lazer e tempo livre nas culturas contemporâneas, com possibilidades de aplicações nas mais diversas áreas da atividade humana e para todas as etapas da vida dos indivíduos, com destaque da importância destas aplicações na vida das crianças e dos idosos.

Trata-se de um livro muito rico, não somente em quantidade, mas, principalmente, em qualidade. São dezesseis capítulos, além de uma introdução bem esclarecedora, apresentando o entrelaçamento do ócio com os mais diversos temas altamente importantes para as culturas contemporâneas, apontando caminhos e possibilidades de perspectivas de pesquisas no tema do ócio e correlatos.

Podemos dizer que agora temos um livro que representa o pensamento de pesquisadores ibero-americanos sobre o ócio nas culturas contemporâneas, mormente sobre a vertente do ócio humanista.

Com certeza, esta obra é e será de grande valor para pesquisadores e estudiosos do ócio, do lazer, do tempo livre e do trabalho que formam a comunidade dos países lusófonos.

Destaca-se este livro, também, pelo fato de ser resultado da cooperação de pesquisadores de instituições de vários países, o que mostra o poder do trabalho colaborativo em rede para a nucleação e o compartilhamento do processo de geração de conhecimento numa área tão essencial para as culturas contemporâneas. Além disso, apresenta-se, concomitantemente, em formato de e-book, permitindo um acesso mais fácil, mais econômico e mais democrático.

Vale a pena conferir.

\section{Referência}

Martins, J. C. O., \& Baptista, M. M. (Orgs.). (2013). O ócio nas culturas contemporâneas: teorias e novas perspectivas em investigação. Coimbra: Grácio.

\section{Endereço para correspondência:}

José Júlio Martins Tôrres

Endereço: Av. Padre Antonio Tomás, no 630, apto. 201, Aldeota. Fortaleza/CE, CEP: 60140-160.

E-mail:jjmtorres@gmail.com 